\title{
CONTROLLING COACHES' BEHAVIOUR, PSYCHOLOGICAL NEED THWARTING, MOTIVATION AND RESULTS OF THE VOLLEYBALL COMPETITIONS
}

\author{
Kaisa Karjane, Vello Hein \\ Institute of Sport Pedagogy and Coaching Sciences, University of Tartu, Tartu, \\ Estonia
}

\begin{abstract}
The aim of the study was to adapt and validate an Estonian version of the Sport Motivation Scale (SMS-II) [21], the Psychological Need Thwarting Scale (PNTS) [5] and Controlling Coach Behaviours Scale (CCBS) [6] in girls' volleyball domain. SMS-II, CCBS and PNTS were assessed in 298 (U-20 42\%, U-16 58\%) volleyball girls from several clubs who took part in U-16 and U-20 Estonian Volleyball Federation Cup in 2015. After modifying the SMS-II, CCBS and PNTS questionnaire, all reliability demonstrated good content. In the top ranking list of the competitions the teams from one to six formed the winner group and six from bottom formed loser group. The older athletes of the winner group (U-20) were more externally motivated and perceived their coaches using more excessive personal control, negative conditional regard than the group of losers. The younger athletes of the winner group (U-16) were less autonomously motivated and perceived their coaches using more negative conditional regard and thwarting need of the competence than the group of losers. The findings of this study showed that youth athletes who are winners or losers perceive their coaches' behavior differently.
\end{abstract}

Keywords: self-determined motivation; psychological need thwarting; coach interpersonal style; competition results

\section{INTRODUCTION}

Sport is important in young people's lives. The benefit of physical activity is frequently related to psychological and physical health. A large number of 
children and youngsters regularly engage in organized sport. Sport central theme is motivation and why people do this. Motivation is related with anxiety, fear of injury [22], burnout [15, 16], well-being [19], concentration [23] and competition result [10]. Gillet et al. [10] found that coaches' autonomy support was related to motivation toward sport activity and motivation predicted the competition results. Hein and Jõesaar [11] made reference that coaches, parents, heroes and peers affect motivational climate in sport context, and the studies of perceived motivational climate are principally based on the climate created by a coach.

In this study authors concentrate on coaches' interpersonal teaching behaviour. There are many researches about autonomy supportive coach behaviour $[1,2,4,11]$ and basic psychological needs satisfaction $[1,2,4]$, but in this study we are looking at the negative side of the human behaviour like psychological need thwarting and the controlling interpersonal style. We might guess that autonomy-supportive and controlling style are two ends of the self-determined continuum line and mutually related such as different types of motivation. Recently, Amoura [3] with her colleagues showed that it is not like that, these are negatively non-significantly correlated. The positive effect of teachers' or coaches' autonomy supportive behaviour on the psychological need satisfaction for autonomy, competence and relatedness which in turn positively related to autonomous motivation is well documented $[1,2,23]$. However, less research evidence exists about the relationships between controlling behaviour and need thwarting [12]. Lack of need satisfaction (i.e. need dissatisfaction) is not equivalent to experiences of need thwarting. In fact, need thwarting better predicted compromised relational functioning compared to need dissatisfaction [5]. Need satisfaction was a stronger predictor of interpersonal competence compared to need thwarting and need dissatisfaction [7]. For instance, a low score on a need satisfaction scale may not necessarily indicate that an athlete feels as if his or her needs are being thwarted during their interactions with the sport coaches; it may merely suggest that the athlete feels dissatisfied with the extent to which his or her needs are currently being met [5].

In order to have more insight on the coaches' interpersonal behaviour and athletes' psychological needs Bartholomew and her colleagues developed questionnaire to measure coaches' controlling behaviour (Controlling Coach Behaviours Scale - CCBS) [6] and need thwarting (Psychological Need Thwarting Scale - PNTS) [5].

Up to date, there are only few studies where the relationships between coaches' behaviour and athletes' motivation in respect of sport competition 
results were investigated $[10,25]$. This study has two aims. Firstly, it aims to validate the measures of CCBS, PNTS and Sport Motivation Scale (SMS-II) among youth Estonian volleyball players [21]. Secondly, the study aims to investigate how winner teams on the final competition differed from loser teams in respect of coaches' controlling behaviour, athletes' need thwarting, and their motivation.

\section{MATERIALS AND METHODS}

The sample included 298 young female volleyball players (U-20 42\%, U-16 $58 \%$ ), who took part in U-20 and U-16 Estonian Volleyball Federation (EVF) Cup in 2015. Competitions were held on 20-22 February 2015 in Pärnu, Narva and Põlva (U-16) and 31 January to 3 February 2015 in Võru, Pärnu and Tallinn (U-20).

The permission to take part in the study was taken from the club coaches, who were supervisors for the players. Participation was voluntary, anonymous and confidential, they were informed about the instructions on how to fill in the questionnaire. The researchers emphasized to the participants that all the questionnaires were designed to measure athletes' own perceptions and there were no right or wrong answers and all questions about the questionnaire were allowed. The athletes completed the questionnaires before or after a game without the presence of a coach.

The coaches' controlling behaviour was measured by CCBS [6] and need thwarting by PNTS [5]. Motivation was measured by SMS II [21]. Athletes responded on 7-point Likert-type scales 1 (strongly disagree) to 7 (strongly agree). The questionnaire took approximately 15-25 minutes to complete. The SMS-II included 15 items to measure intrinsic regulation, identified regulation, introjected regulation, external regulation and amotivated regulation factors. In this study, a measure of integrated regulation was not included, because integrated regulation is not usually assessed in research on adolescents, since it requires a high degree of introspection and selfawareness [18]. The PNTS included 12 need thwarting items to measure autonomy, competence and relatedness factors. The CCBS included 15 items to measure controlling use of rewards, negative conditional regard, intimidation and excessive personal control factors.

\section{Statistical analysis}

The data were analysed using the LISREL 8.8 and SPSS 20. Cronbach's alphas were calculated for all items to assess the internal reliability of the subscales, 
acceptable level was 0.70 [20]. Group comparison was made by independent sample t-test.

Confirmatory factor analyses (CFA) were used to test the validity the factor structure of the instruments. Goodness-of-fit of the model with the data was evaluated using multiple recommended indexes of good-fit: the Comparative Fit Index (CFI), the Non-Normed Fit Index (NNFI), the Normed Fit Index (NFI) and Root Mean Square Error of Approximation (RMSEA). For CFI, NNFI and NFI acceptable values was above 0.9 and for RMSEA value should be between 0.05 and 0.08 [13].

Eighteen teams participated on U-20 EVF cup competition. Teams were divided into two groups according to the competition results. In the top ranking list the teams from one to six formed the winner group and six form bottom formed loser group. Twenty four teams participated on U-16 EVF cup competition. In the top ranking list the teams from one to six formed the winner group and six form bottom formed loser group.

\section{RESULTS}

The reliability coefficient of the external regulation subscale from SMS-II was not on acceptable level. Elimination item "Because people around me reward me when I do" resulted in increased reliability coefficient from 0.67 to 0.79 and decreased RMSEA from 0.068 to 0.060 . In respect of CCBS, the reliability coefficient of the controlling use of rewards subscale was also not on acceptable level. Elimination the item "My coach tries to motivate me by promising to reward me if I do well" resulted in increased reliability coefficient from 0.64 to 0.77 and the goodness of fit statistics improved. The reliability coefficient of relatedness subscale from PNTS was not on acceptable level and the factor loading was only 0.29 . Elimination the item "I feel other people are envious when I achieve success" resulted in increased reliability coefficient from 0.64 to 0.77.The goodness of fit indices for SMS-II, CCBS and PNTS are reported in Table 1 and SMS-II confirmatory factor structure is presented in Figure 1. 
Table 1. The goodness of fit statistics of Sport Motivation Scale II, Psychological Need Thwarting Scale and Controlling Coach Behaviours Scale

\begin{tabular}{|c|c|c|c|c|c|c|}
\hline Questionnaire & $S-B \chi^{2}$ & CFI & NNFI & NFI & RMSEA & $\mathrm{Cl}_{95} \mathrm{RMSEA}$ \\
\hline \multicolumn{7}{|l|}{ 1. Original Sport Motivation } \\
\hline Scale II & 190.56 & 0.97 & 0.97 & 0.96 & 0.068 & $0.056-0.081$ \\
\hline $\begin{array}{l}\text { 2. Modified version without } \\
\text { external regulation second } \\
\text { question }\end{array}$ & 138.24 & 0.97 & 0.97 & 0.96 & 0.060 & $0.046-0.074$ \\
\hline \multicolumn{7}{|l|}{ 3. Original Controlling Coach } \\
\hline Behaviours Scale & 198.16 & 0.98 & 0.98 & 0.97 & 0.068 & $0.055-0.80$ \\
\hline $\begin{array}{l}\text { 4. Modified version without } \\
\text { controlling use of rewards first } \\
\text { question }\end{array}$ & 159.89 & 0.99 & 0.98 & 0.98 & 0.065 & $0.051-0.078$ \\
\hline \multicolumn{7}{|l|}{ 5. Original Psychological Need } \\
\hline Thwarting Scale & 131.11 & 0.98 & 0.97 & 0.96 & 0.073 & $0.057-0.088$ \\
\hline $\begin{array}{l}\text { 6. Modified version without } \\
\text { relatedness fourth question }\end{array}$ & 117.16 & 0.98 & 0.97 & 0.97 & 0.079 & $0.062-0.096$ \\
\hline
\end{tabular}

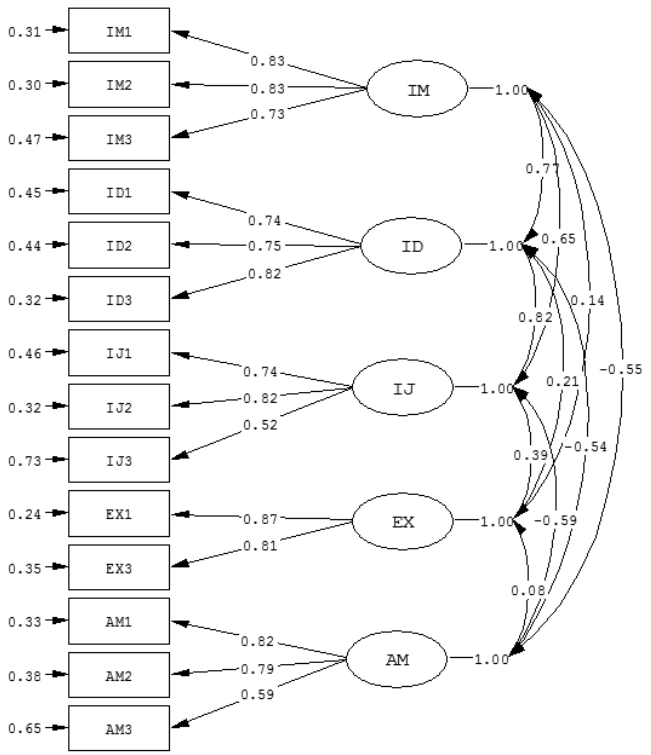

Figure 1. Confirmatory Factor Analysis of the SMS-II

Notes: IM - intrinsic regulation; ID - identified regulation; IJ - introjected regulation; EX - external regulation $\mathrm{AM}$ - amotivated regulation All paths are significant at $p<0.01$ 
The differences between the winner and loser groups in respect of controlling types of teacher behaviour, dimensions of psychological need thwarting and types of motivation are presented in Table 2. The winner and loser groups of older volleyball players (U-20) were significantly different from external regulation, excessive personal control, negative conditional regard and intimidation. Players of winner groups perceived coaches' controlling behavior in all dimensions more than players of loser groups, except the controlling use of rewards. The group of winner was significantly higher externally motivated than group of loser, whereas no differences were found in other types of motivation. Perceived psychological needs thwarting were not different between groups.

Table 2. The coaches' controlling behaviour, athletes'need thwarting and their motivation of winner and loser groups

\begin{tabular}{lcc|cc|c|cc|cc|c}
\hline & \multicolumn{2}{c}{$\begin{array}{c}\text { U-20 } \\
\text { winner gr }\end{array}$} & \multicolumn{2}{c|}{$\begin{array}{c}\text { U-20 } \\
\text { loser gr }\end{array}$} & Sig & \multicolumn{2}{c|}{$\begin{array}{c}\text { U-16 } \\
\text { winner gr }\end{array}$} & \multicolumn{2}{c|}{$\begin{array}{c}\text { U-16 } \\
\text { loser gr }\end{array}$} & Sig \\
\cline { 2 - 10 } & Mean & SD & Mean & SD & & Mean & SD & Mean & SD & \\
\hline IMM & 6.02 & 1.01 & 6.01 & 1.04 & & 6.09 & 0.91 & 6.70 & 0.53 & $* * *$ \\
\hline IDM & 5.66 & 1.10 & 5.62 & 1.07 & & 5.73 & 1.17 & 6.44 & 0.63 & $* * *$ \\
\hline IJM & 5.17 & 1.14 & 5.29 & 1.01 & & 5.07 & 1.35 & 5.59 & 1.07 & $*$ \\
\hline EX13M & 3.93 & 1.83 & 2.41 & 1.39 & $* *$ & 3.86 & 2.21 & 3.41 & 1.94 & \\
\hline AMM & 2.73 & 1.41 & 3.10 & 1.62 & & 2.21 & 1.42 & 1.77 & 1.03 & \\
\hline EPCM & 4.18 & 1.58 & 2.17 & 1.13 & $* *$ & 2.34 & 1.49 & 1.87 & 1.22 & \\
\hline CUR234M & 2.83 & 1.30 & 3.38 & 1.38 & & 2.25 & 1.26 & 2.23 & 1.20 & \\
\hline NCRM & 4.00 & 1.48 & 2.59 & 1.55 & $* *$ & 2.55 & 1.44 & 1.98 & 1.01 & $*$ \\
\hline INTM & 3.60 & 1.55 & 2.32 & 1.54 & $* *$ & 2.05 & 1.04 & 1.65 & 1.16 & \\
\hline TAUTM & 3.34 & 1.42 & 3.12 & 1.33 & & 2.64 & 1.31 & 2.28 & 0.95 & \\
\hline TREL123M & 1.99 & 1.02 & 2.26 & 1.45 & & 1.65 & 0.97 & 1.57 & 0.94 & \\
\hline TCOMPM & 3.63 & 1.28 & 3.40 & 1.84 & & 3.08 & 1.56 & 2.47 & 1.22 & $*$ \\
\hline
\end{tabular}

Note: gr - group; sig - significant; ${ }^{* * *}-\mathrm{P}<0.001 ;{ }^{* *}-\mathrm{P}<0.01 ;{ }^{*}-\mathrm{P}<0.05$; IMM - intrinsic regulation mean; IDM - identified regulation mean; IJM - introjected regulation mean; EX13M - external regulation first and third question mean; AM - amotivated regulation mean; EPCM - excessive personal control mean; CUR234M - controlling use of rewards second, third and fourth question mean; INTM - Intimidation mean; NCRM - Negative Conditional Regard mean; TAUTM - thwarting of the autonomy mean; TREL123M thwarting of the relatedness mean; TCOMPM - thwarting of the competence mean 
The winner and loser groups of younger volleyball players (U-16) were significantly different from intrinsic regulation, identified regulation, introjected regulation, negative conditional regard and thwarting of the competence. All motivation types, except external regulation and amotivation, were higher among players of winner group than players of loser group. The group of winner perceived significantly higher negative conditional regard and need thwarting of the competence than group of loser. In coach controlling behaviour only negative conditional regard was higher in winner group than in loser group; the perception of other dimensions was not different between groups. Perceived psychological needs thwarting were not different between groups; expect competence.

\section{DISCUSSION}

The purpose of the present study was to validate an Estonian version of CCBS [6], PNTS [5] and SMS-II [21] among girls' volleyball players. These instruments [12] were former used in PE context with Estonian school children and also indicated the existence of the validity. The results of this study showed that youth volleyball players were intrinsically and externally motivated, however their intrinsic motivation in comparison of external motivation was higher. This result is consistent with several previous studies [9, 17] where elite athletes were motivated by both internally as externally.

In the Vansteenkise and Deci [24] study, the athletes who won the competition were more intrinsically motivated than losers. Losers who received positive feedback were more intrinsically motivated than losers who did not. Obviously, it is one of the explanation why losers were intrinsically more motivated than winners among younger athletes (U-16) in the present study. However, for older athletes no differences in respect of intrinsic motivation were followed. In contrast, winners were more externally motivated than losers. The winner perceived their coaches' behavior more controlling than losers. Consequently, coaches who wished that their athletes would be winner applied more controlling behavior. According to self-determination theory [8], several researchers $[5,6]$ have reported that controlling behaviour will lead to external motivation and autonomy supportive behavior to intrinsic motivation. Although, externally motivation facilitates to win the competition, in the long term it may cause the drop out from sport [15].

The findings of the present study showed that the players from winner group perceived their coaches more controlling than players from loser group. The same trend was followed in respect of external motivation. The 
results of this study in some extent corroborate the findings obtained in the experimental study of Amoura [3], where students' group who got their tasks in the low autonomy and high control condition led to the highest situational self-determined motivation. In general, young people are going to the sport training and competitions on a voluntary basis, and current situation was similar to Amoura [3] experiment, but Gillet [10] showed that higher results were related to autonomy supportive behaviours. Therefore, the future studies should look both behaviours (autonomy and controlling) together, because first one cannot rule out the second one [3].

Although this study provides new information into the area of coaches' behaviour effects on the results, there are limitations that should be noted. Firstly, this study was a cross-sectional research design. Given the dynamic relationship between the coach and the athlete, coaches controlled behaviours fluctuation during the season and even during the competition is obvious. For example, longitudinal studies are recommended to capture the dynamic variations throughout the season or competitions. Secondly, age and training experiences of players were not considered which may affected the results. For instance, for players on both competitions (U-20 and U-16) upper age limit were applied but lower age limit were not. Consequently, the players who were younger were allowed to participate on U-20 and U-16 competition. Therefore, in the future study to have more insight on the players' perception the coaches' controlling behavior and their motivation in respect of competition results the age and training experience need to take into account. Thirdly, here were only volleyball players, and in the future should be taken part in other similar sports, for example basketball, football and indiaca.

In summary, we believe that the present findings contribute to our understanding how the volleyball players of the winners differ from the losers in respect of coaches' behaviour and motivation and they have to consider this in coaching processes. For deeper understanding more detailed and comprehensive analysis is needed to explore the coaches' behavior on the results of the sport competitions.

\section{REFERENCES}

1. Adie JW, Duda JL, Ntoumanis N. (2012) Perceived coach-autonomy support, basic need satisfaction and the well- and ill-being of elite youth soccer players: A longitudinal investigation. Psychol Sport Exerc, 13: 51-60 
2. Amorose AJ, Anderson-Butcher D. (2007) Autonomy-supportive coaching and self-determined motivation in high school and college athletes: A test of selfdetermination theory. Psychol Sport Exerc, 8: 654-670

3. Amoura C, Berjot S, Gillet N, Caruana S, Finez L. (2015) Effects of autonomysupportive and controlling styles on situational self-determined motivation: some unexpected results of the commitment procedure. Psychol Rep, 116: 33-59

4. Banack HR, Sabiston CM, Bloom GA. (2011) Coach autonomy support, basic need satisfaction, and intrinsic motivation of paralympic athletes. Res Q Exerc Sport, 82: 722-730

5. Bartholomew KJ, Ntoumanis N, Ryan RM, Thøgersen-Ntoumani C. (2011) Psychological need thwarting in the sport context: assessing the darker side of athletic experience. J Sport Exerc Psychol, 33: 75-102

6. Bartholomew KJ, Ntoumanis N, Thøgersen-Ntoumani C. (2010) The controlling interpersonal style in a coaching context: development and initial validation of a psychometric scale. J Sport Exerc Psychol, 32: 193-216

7. Costa S, Ntoumanis N, Bartholomew KJ. (2015) Predicting the brighter and darker sides of interpersonal relationships: Does psychological need thwarting matter? Motiv Emot, 39: 11-24

8. Deci EL, Ryan RM. (1985) Intrinsic motivation and self-determination in human behavior. New York: Plenum Press

9. Gillet N, Rosnet E. (2008) Basic need satisfaction and motivation in sport. Online J Sport Psychol, 10

10. Gillet N, Vallerand RJ, Amoura S, Baldes B. (2010) Influence of coaches' autonomy support on athletes' motivation and sport performance: A test of the hierarchical model of intrinsic and extrinsic motivation. Psychol Sport Exerc, 11: 155-161

11. Hein V, Jõesaar H. (2015) How perceived autonomy support from adults and peer motivational climate are related with self-determined motivation among young athletes. Int J Sport Exerc Psychol, 13: 193-204

12. Hein V, Koka A, Hagger MS. (2015) Relationships between perceived teachers' controlling behaviour, psychological need thwarting, anger and bullying behaviour in high-school students. J Adolesc, 42: 103-114

13. Hu L, Bentler PM. (1999) Cutoff criteria for fit indexes in covariancestructure analysis: Conventional criteria versus new alternatives. Struct Equ Modeling, 6: $1-55$

14. Jõesaar H, Hein V. (2011) Psychosocial determinants of young athletes' continued participation over time. Percept Mot Skills, 113: 51-66

15. Li C, Wang CKJ, Pyun DY, Kee YH. (2013) Burnout and its relations with basic psychological needs and motivation among athletes: A systematic review and meta-analysis. Psychol Sport Exerc, 14: 692-700 
16. Lonsdale C, Hodge K. (2011) Temporal ordering of motivational quality and athlete burnout in elite sport. Med Sci Sports Exerc, 43: 913-921

17. Mallett CJ, Hanrahan SJ. (2004) Elite athletes: why does the 'fire' burn so brightly? Psychol Sport Exerc, 5: 183-200

18. Meyer JD, Tallir I, Soenens B, Speleers L, Haerens L. (2014) Does observed controlling teaching behavior relate to students' motivation in physical education? J Educ Psychol, 106: 541-554

19. Mouratidis A, Vansteenkiste M, Lens W, Sideridis G. (2008) The motivating role of positive feedback in sport and physical education: evidence for a motivational model. J Sport Exerc Psychol, 30: 240-268

20. Nunnally JC. (1970) Introduction to psychological measurement. New York: McGraw-Hill

21. Pelletier LG, Rocchi MA, Vallerand RJ, Deci EL, Ryan RM. (2013) Validation of the revised sport motivation scale (SMS-II). Psychol Sport Exerc, 14: 329-341

22. Podlog L, Eklund RC. (2005) Return to sport after serious injury: a retrospective examination of motivation and psychological outcomes. J Sport Rehabil, 14: $15-20$

23. Standage M, Duda JL, Ntoumanis N. (2005) A test of self-determination theory in school physical education. Brit J Educ Psychol, 75: 411-433

24. Vansteenkiste M, Deci EL. (2003) Competitively contingent rewards and intrinsic motivation: can losers remain motivated? Motiv Emot, 27: 273-299

25. Vassil K. (2014) The effect between peer motivational climate and sport competition results on Estonian U-18 age class volleyball players. Inst Sport Pedagogy Coach Sci, Tartu

\section{Correspondence to:}

Kaisa Karjane

Institute of Sport Pedagogy and Coaching Sciences

Faculty of Exercise and Sport Sciences

University of Tartu

5 Jakobi Street, 51014 Tartu

Estonia

kaisakarjane@gmail.com 